\title{
Epidemiology, associated burden, and current clinical practice for the diagnosis and management of Alzheimer's disease in Japan
}

This article was published in the following Dove Press journal:

ClinicoEconomics and Outcomes Research

\author{
William Montgomery' \\ Kaname Ueda ${ }^{2}$ \\ Margaret Jorgensen ${ }^{3}$ \\ Shari Stathis ${ }^{3}$ \\ Yuanyuan Cheng ${ }^{3}$ \\ Tomomi Nakamura ${ }^{2}$ \\ 'Global Patient Outcomes \& Real \\ World Evidence, Eli Lilly Australia, \\ Sydney, NSW, Australia; ${ }^{2}$ Medical \\ Development Unit-Japan, Eli Lilly \\ Japan KK, Kobe, Japan; ${ }^{3}$ Health \\ Technology Analysts, Lilyfield, NSW, \\ Australia
}

Correspondence: Kaname Ueda Medical Development Unit-Japan, Eli Lilly Japan KK, 7-I-5, Isogami-dori, Chuo-ku, Kobe 85I0086, Japan

$\mathrm{Tel}+81782429519$

Email ueda_kaname@lilly.com

\begin{abstract}
The burden of dementia in Japan is large and growing. With the world's fastest aging population, it is estimated that one in five elderly people will be living with dementia in Japan by 2025. The most common form of dementia is Alzheimer's disease (AD), accounting for around two-thirds of dementia cases. A systematic review was conducted to examine the epidemiology and associated burden of AD in Japan and to identify how AD is diagnosed and managed in Japan. English and Japanese language databases were searched for articles published between January 2000 and November 2015. Relevant Japanese sources, clinical practice guideline registers, and reference lists were also searched. Systematic reviews and cohort and case-control studies were eligible for inclusion, with a total of 60 studies included. The most recent national survey conducted in six regions of Japan reported the mean prevalence of dementia in people aged $\geq 65$ years to be $15.75 \%$ ( $95 \% \mathrm{CI}: 12.4,22.2 \%)$, which is much higher than the previous estimated rate of $10 \%$ in 2010 . AD was confirmed as the predominant type of dementia, accounting for $65.8 \%$ of all cases. Advancing age and low education were the most consistently reported risk factors for AD dementia. Japanese guidelines for the management of dementia were released in 2010 providing specific guidance for AD about clinical signs, image findings, biochemical markers, and treatment approaches. Pharmacotherapies and non-pharmacotherapies to relieve cognitive symptoms were introduced, as were recommendations to achieve better patient care. No studies reporting treatment patterns were identified. Due to population aging and growing awareness of AD in Japan, health care expenditure and associated burden are expected to soar. This review highlights the importance of early detection, diagnosis, and treatment of AD as strategies to minimize the impact of AD on society in Japan.
\end{abstract}

Keywords: dementia, risk factors, treatment patterns, systematic review

\section{Introduction}

Alzheimer's disease (AD) is an irreversible, progressive brain disorder that slowly deteriorates the healthy brain, thereby affecting a person's memory, thinking skills, emotions, behavior, and mood. Over time, a person's ability to carry out daily activities becomes impaired. AD is the most common form of dementia, accounting for $\sim 60 \%-80 \%$ of cases. ${ }^{1}$ The 2015 World Alzheimer Report indicated there were 46.8 million people living with dementia worldwide, with the projected number of cases almost doubling every 20 years. ${ }^{2}$ In Japan, a 2013 study commissioned by the Ministry of Health, Labour and Welfare (MHLW) reported that more than 4.6 million Japanese were living with dementia. ${ }^{3}$ This number is expected to reach 7 million in 2025 , representing approximately one in five elderly people in Japan. ${ }^{4}$ 
Patients who are memory impaired but have limited functional impairment and do not meet clinical criteria for dementia are classified as having mild cognitive impairment (MCI), ${ }^{5-7}$ or mild neurocognitive disorder as defined in the most recent Diagnostic and Statistical Manual of Mental Disorders V. Increasingly, MCI is recognized as an important health care issue because of its association with significant morbidity, including the development of dementia and $\mathrm{AD}$ dementia. ${ }^{9} \mathrm{MCI}$ is a heterogeneous clinical syndrome, and new criteria for MCI due to $\mathrm{AD}$ are intended to help increase the accuracy of diagnosing $\mathrm{AD}$ in the pre-dementia stage. ${ }^{7}$

In addition to cognitive impairments, more than $50 \%$ of patients with dementia experience behavioral and psychological symptoms of dementia (BPSD), which include apathy, dysphoria (eg, depressive mood and sadness), euphoria, anxiety, irritability, social withdrawal, sundowning, sleep disorders, suspiciousness, disinhibition, disturbing behavior, delusions, hallucinations, stereotyped or repetitive behavior, and agitation or aggression. ${ }^{10} \mathrm{BPSD}$ are distressing for patients and their caregivers and are often the reason for admission of patients into residential care. ${ }^{10,11}$ Psychotropic medications have been extensively prescribed for the treatment of BPSD but are associated with increased mortality in patients. The death rate of elderly patients with dementia who were treated with atypical antipsychotic agents is estimated to be 1.6-1.7 times that of patients treated with placebo. ${ }^{12}$ Additional comorbidities include pneumonia; cardiovascular diseases such as hypertension and cardiac infarction; stroke; diabetes mellitus; and tumors. ${ }^{13-15}$ These concomitant diseases may play a role in increasing the mortality rate of dementia.

The specific aim of this study was to conduct a systematic review of both the English and Japanese published literature on 1) the epidemiology of AD in Japan, including prevalence, incidence, conversion rate from MCI to dementia and/or AD dementia, comorbidity, mortality, and risk factors; 2) guidelines for treatment and real-world treatment patterns; and 3) the associated economic burden of AD in Japan, including direct and indirect costs, quality of life, and economic evaluations. The results of the first two reviews are presented here, with a follow-up report on the economic burden of $\mathrm{AD}$ in Japan to be published separately.

\section{Materials and methods}

Electronic searches of three English databases (MEDLINE, EMBASE, the Cochrane library) and one Japanese database (ICHUSHI-WEB) were conducted in November 2015 for studies reporting on AD in Japan. The searches focused on the following: 1) epidemiology and 2) treatment guidelines and treatment patterns. EMBASE and MEDLINE searches were conducted via the OVID interface on November 11, 2015. The search strategies were modified and repeated in the Cochrane Library databases on November 17, 2015. The ICHUSHIWEB database was searched on November 27, 2015. Each search comprised indexed keywords (subject headings) and free text terms appearing in titles and/or abstracts. Search terms included Alzheimer's disease, treatment guidelines, treatment pattern, medication use, prevalence, incidence, and risk factors. Details of each search strategy are provided in the Supplementary material.

Supplementary searches to identify any ongoing clinical trials, gray literature, or clinical practice guidelines were conducted using the following sources: University Hospital Medical Information Network Clinical Trials Registry (UMIN-CTR), World Health Organization International Clinical Trials Registry Platform (ICTRP), Japanese Ministry of Health, Labour and Welfare, National Institute for Health and Care Excellence (NICE), Canadian Agency for Drugs and Technologies in Health (CADTH), Agency for Healthcare Research and Quality (AHRQ), National Guidelines Clearing House, and Guidelines International Network. Reference lists of relevant articles identified for inclusion were also search for additional studies and reviews.

Records returned from each search were screened for eligibility using predefined reasons for exclusion. The main inclusion criteria included adults aged $\geq 18$ years with $A D$ in Japan. Articles were included if they were published in the English or Japanese language. Conference proceedings, books, and articles in press were eligible for inclusion, as were systematic reviews, prospective and retrospective population studies, and observational studies. Editorials, case reports, and general review articles were excluded. No date restrictions were applied to the search strategy; however, articles published prior to 2000 were not screened to avoid historical references to $\mathrm{AD}$ prevalence or treatment guidance provided prior to the approval of donepezil in Japan. The main exclusion criteria were as follows: non-human study, not a study of AD in adults, study that did not focus on Japanese population, or study that did not include at least one outcome relevant to this review, such as treatment patterns, guidelines for treatment, disease prevalence, incidence, morbidity, mortality, or factors influencing dementia or AD risk. Studies that enrolled fewer than 100 patients were excluded, as were studies with insufficient reporting of data. Relevant review articles were carefully screened to ensure that all primary 
studies were identified and that any duplicate citations were identified.

One systematic reviewer (SS) independently screened all titles and abstracts identified in the English databases to find citations that met the inclusion criteria and were relevant for full-text review. Quality checks to ensure whether inclusion criteria were appropriately applied were made by a second reviewer (MJ). Any disagreements regarding screening and study selection were resolved by consensus (SS, YC, MJ). The process for study selection was replicated for articles identified in the Japanese database by one independent reviewer (YC) with the exception that titles in Japanese were first screened in that language by an independent provider, and then abstracts identified for inclusion were translated into English and rescreened (YC) prior to full-text review.

After full-text review, relevant data were extracted into prespecified tables by one reviewer (SS) and checked by a second reviewer (YC). Quality appraisal of included studies was not conducted. Descriptive variables extracted for all included studies were author, year of publication, study design, and population characteristics (eg and age, disease severity). Additional variables extracted from epidemiology studies were prevalence, incidence, morbidity, mortality, and risk factors associated with dementia. Additional variables extracted from treatment guidelines were recommendations regarding diagnosis, pharmacologic and non-pharmacologic interventions, and patient care. Studies reporting on mixed populations of dementia and $\mathrm{AD}$ were included, with the intention that data for $\mathrm{AD}$ be isolated from the broader population group. Attempts to derive information relating to the stages of $\mathrm{AD}$ (mild, moderate, and severe) were also to be made.

\section{Results}

A PRISMA flow ${ }^{16}$ presenting the results of the screening and selection process of articles identified in the English and Japanese databases is shown in Figure 1. The combined English and Japanese language databases identified 1223 articles relating to prevalence, incidence, morbidity, mortality, and risk factors of AD in Japan. After removal of duplicates and studies published prior to 2000, 1111 citations were screened for inclusion, including two additional records identified through manual searching. Of these, 69 articles were identified as potentially relevant for inclusion, with 33 studies excluded after full-text review. A list of these studies, with reasons for exclusion, is presented in the Supplementary material. In total, there were 36 studies identified for inclusion that reported on the epidemiology of AD in Japan, including systematic reviews, prospective cohort studies, retrospective cohort studies, and case-control studies.

From an initial 1567 citations relating to current clinical practice in Japan for the diagnosis and management of AD, 1525 citations were screened for suitability, including one article identified through manual searching. Of these, 43 articles were identified that potentially met the inclusion criteria, with 33 studies excluded after full-text review (Supplementary material). In total, 10 relevant papers relating to pharmacologic and non-pharmacologic treatment of AD in Japan were identified. None of the identified studies provided information relating to real-world treatment patterns.

\section{Epidemiology of AD in Japan}

\section{Prevalence}

Studies that reported on dementia and/or AD prevalence across Japan are summarized in Table $1 .{ }^{17-21}$ Overall, the studies indicated the prevalence of all-cause dementia to be increasing in Japan, with a progressive rise in the prevalence of $\mathrm{AD}$ relative to vascular dementia $(\mathrm{VaD})$ occurring. The evidence for a rise in $\mathrm{AD}$ is limited by variations in diagnostic criteria, changing age structures, and gender and regional variability.

A high-quality epidemiological survey on lifestyle-related diseases, ongoing since 1961 in Hisayama-cho, was identified to have conducted five prevalence studies of dementia (1985, 1992, 1998, 2005, and 2012) in all residents aged $\geq 65$ years. ${ }^{17,22}$ The distribution of age, occupation, and nutrition intake of residents in Hisayama have remained at the mean level in Japan for the past 50 years and represent a typical Japanese sample population with few deviations. The prevalence studies were characterized by high accuracy, with high participation rates $(92 \%-99 \%)$ and few dropouts from follow-up study $(<1 \%)$, and included a morphological examination of the brain by cranial computed tomography/ magnetic resonance imaging and autopsy ( $80 \%$ of autopsy rate) for reevaluation of etiological dementia subtypes. ${ }^{22}$

Based on the first four prevalence studies conducted in Hisayama between 1985 and 2005, Sekita et al ${ }^{17}$ concluded that the prevalence of all-cause dementia and AD in the general Japanese population had significantly increased over the past two decades. The age- and sex-adjusted prevalence of all-cause dementia increased from $6.0 \%$ in 1985 to $8.3 \%$ in 2005 ( $p$-trend $=0.002$ ) and was 1.34-fold higher in 2005 than in 1985 ( $p=0.08$ ). This trend was observed in the age- and sexadjusted prevalence of all-cause dementia for both sexes but was only significant for women ( $p$-trend $=0.007$ ). The age- and sex-adjusted prevalence of AD increased from $1.1 \%$ in 1985 
A

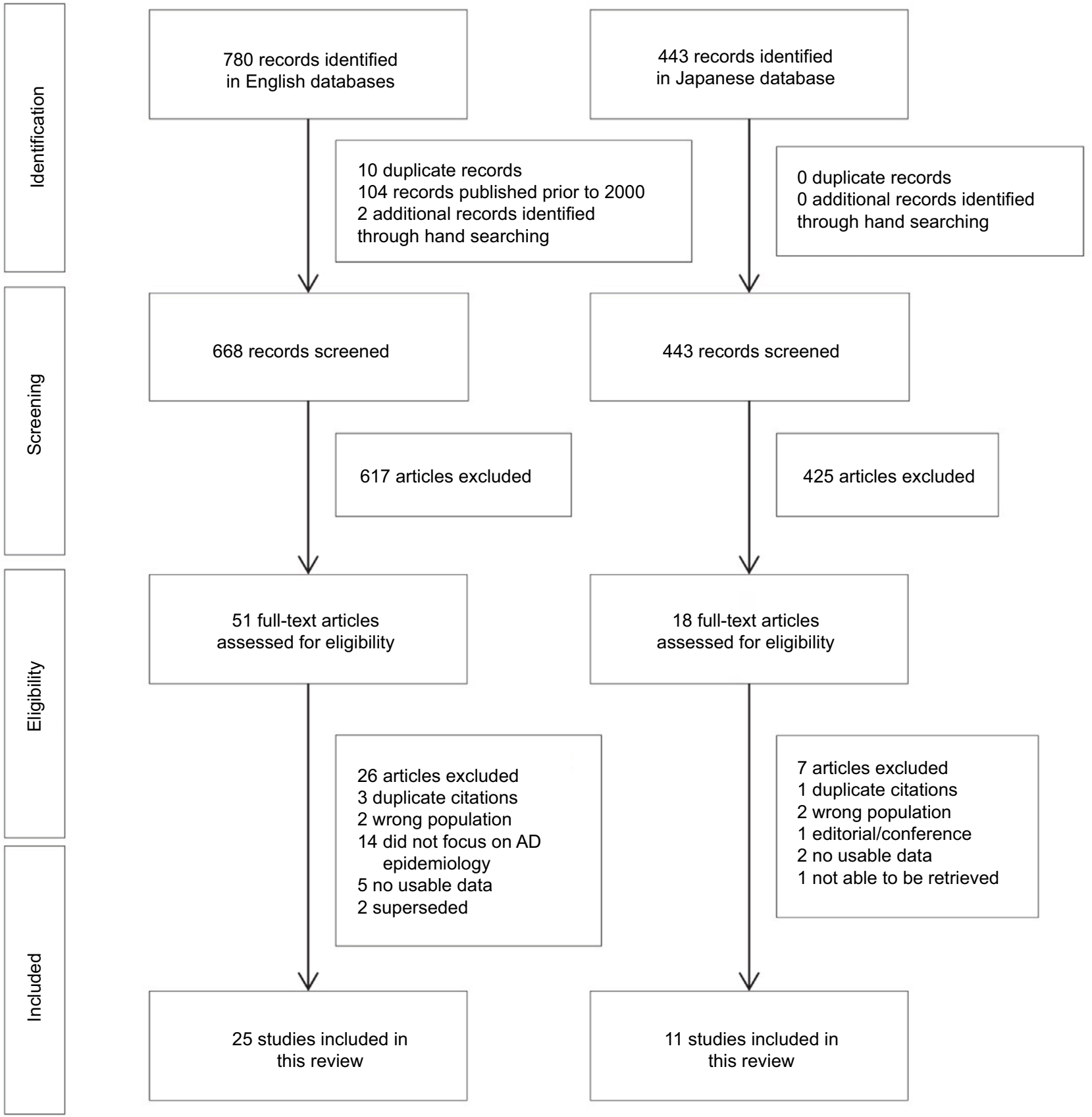

Figure I (Continued) 
B

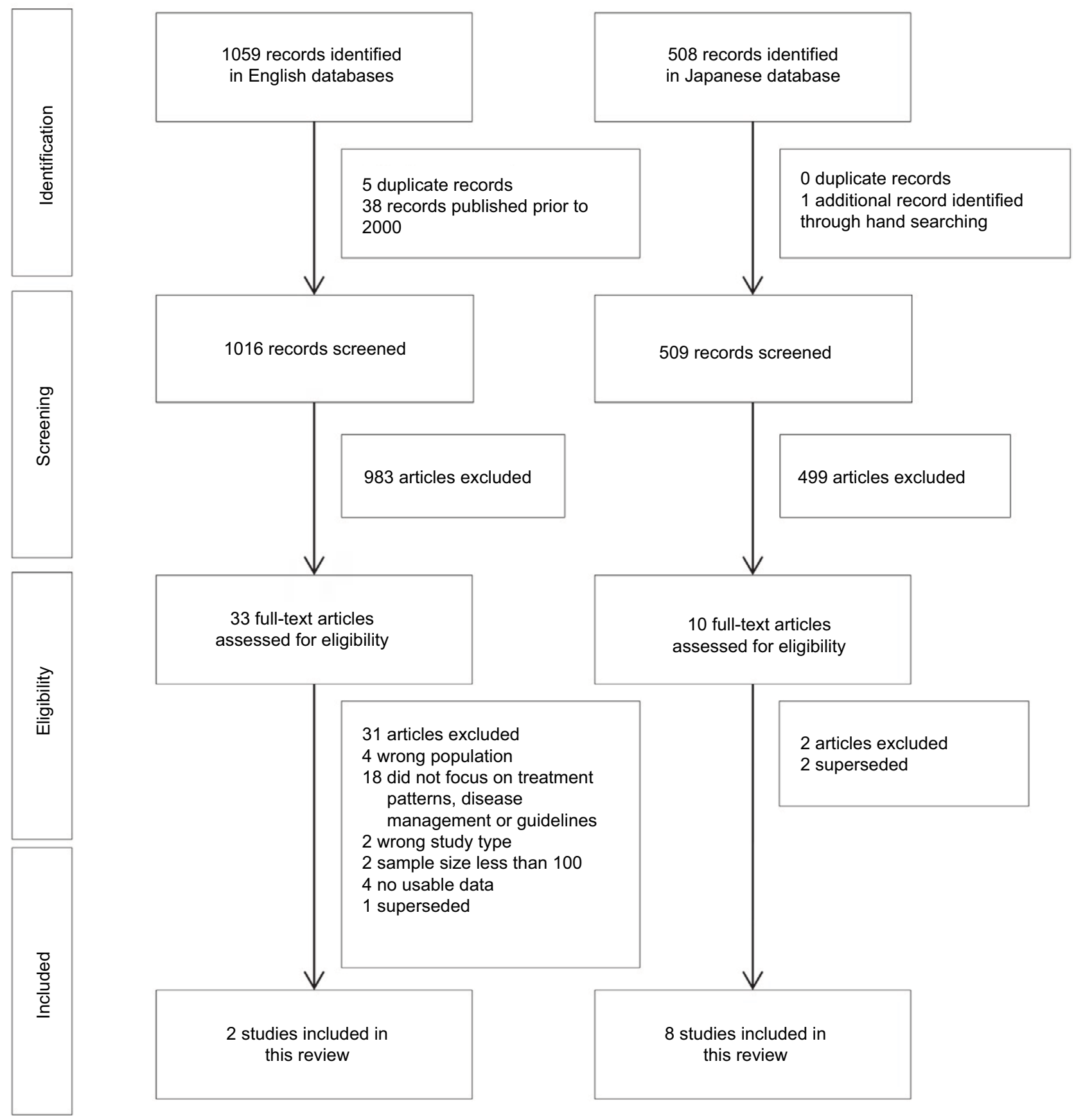

Figure I Selection of studies relating to AD in Japan: (A) epidemiology and (B) treatment patterns and clinical practice guidelines.

Abbreviation: $A D$, Alzheimer's disease.

to $3.8 \%$ in 2005 ( $p$-trend $<0.001$ ) and was 3.28-fold higher in 2005 than in $1985(p<0.001)$. The age- and sex-adjusted prevalence of $\mathrm{VaD}$ was reported to decrease from $2.3 \%$ in 1985 to $1.5 \%$ in 1998 and then increase to $2.5 \%$ in 2005 . Thus, the ratio of $\mathrm{VaD}$ prevalence to that of $\mathrm{AD}$ prevalence decreased with time (2.1 in 1985, 1.2 in 1992, 0.7 in 1998, and 0.7 in 2005).
In 2012, the fifth cross-sectional Hisayama study was conducted, with the point prevalence of dementia continuing to rise from $7.1 \%$ in 1998 to $12.5 \%$ in 2005 and to $17.9 \%$ in 2012. ${ }^{22}$ After adjustments for age and sex, this increasing trend was reported to remain (data not reported) and it was suggested that the prevalence of all-cause dementia has increased beyond the speed of aging. A significant increase in $\mathrm{AD}$ prevalence 
Table I Reported prevalence of dementia and/or Alzheimer's disease in Japan

\begin{tabular}{|c|c|c|c|c|c|}
\hline \multirow[t]{2}{*}{ Study } & \multicolumn{2}{|l|}{ Population } & \multicolumn{2}{|l|}{ Prevalence, \% (95\% Cl) } & \multirow{2}{*}{$\begin{array}{l}\text { Proportion of } \mathbf{A D} \text {, } \\
\%\end{array}$} \\
\hline & Region (study year/s) & $\begin{array}{l}\text { Age, yrs } \\
\text { (popl aging rate) }\end{array}$ & All-cause dementia & $\begin{array}{l}\text { Dementia due to } \\
\text { AD }\end{array}$ & \\
\hline & & & Age-sex-adjusted & Age-sex-adjusted & \\
\hline Sekita et al, ${ }^{17} 2010$ & Hisayama (1985) & $\geq 65$ & $6.0(4.4,7.6)$ & I.I $(0.4, \mathrm{I} .7)$ & NR \\
\hline (cross-sectional & Hisayama (1992) & $\geq 65$ & $4.4(3.3,5.6)$ & $1.3(0.7,1.9)$ & NR \\
\hline \multirow[t]{15}{*}{ study) } & Hisayama (1998) & $\geq 65$ & $5.3(4.2,6.4)$ & $2.3(1.6,3.0)$ & NR \\
\hline & Hisayama (2005) & $\geq 65$ & $8.3(7.0,9.5)$ & $3.8(3.0,4.6)$ & NR \\
\hline & & & Trend, $p=0.002$ & Trend, $p<0.00 \mathrm{I}$ & \\
\hline & $\mathrm{F}$ & & Age-adjusted & & \\
\hline & Hisayama (1985) & & $6.6(4.5,8.6)$ & NR & NR \\
\hline & Hisayama (1992) & & $5.3(3.8,6.8)$ & NR & NR \\
\hline & Hisayama (1998) & & $6.4(4.9,7.9)$ & NR & NR \\
\hline & Hisayama (2005) & & $9.3(7.7,10.9)$ & NR & NR \\
\hline & & & Trend, $p=0.007$ & & \\
\hline & $M$ & & Age-adjusted & & \\
\hline & Hisayama (1985) & & $5.4(3.0,7.8)$ & NR & NR \\
\hline & Hisayama (1992) & & $3.6(1.9,5.3)$ & NR & NR \\
\hline & Hisayama (1998) & & $4.2(2.6,5.9)$ & NR & NR \\
\hline & Hisayama (2005) & & $7.2(5.3,9.2)$ & NR & NR \\
\hline & & & Trend, $p=0.13$ & & \\
\hline Asada, ${ }^{18} 2012$ & Baseline: October, I 2009 & $\geq 65$ & $15.75(\mid 2.4,22.2)$ & 10.36 (calculated) & 65.8 \\
\hline \multirow[t]{6}{*}{ (National survey) } & Ama-cho, Shimane & $(38.0 \%)$ & 15.7 & NR & NR \\
\hline & Joetsu City, Niigata & $(26.2 \%)$ & 20.2 & NR & NR \\
\hline & Tone-machi, Ibaraki & $(26.7 \%)$ & 14.0 & $N R$ & NR \\
\hline & Obu City, Ehime & $(17.2 \%)$ & 12.4 & NR & NR \\
\hline & Kitsuki city, Oita & $(30.9 \%)$ & 15.3 & NR & NR \\
\hline & Imari City, Saga & $(30.7 \%)$ & 14.9 & NR & NR \\
\hline Catindig et al, ${ }^{19} 2012$ & Nakayama (2000) & $>65$ & 4.2 & 1.5 & NR \\
\hline \multirow[t]{5}{*}{$(\text { review) })^{\mathrm{a}}$} & Tajiri (200I) & $>65$ & 8.5 & 7.2 & NR \\
\hline & Kanagawa (2003) & $>65$ & 4.7 & I.I & NR \\
\hline & Osaki-Tajiri (2006) & $>65$ & 26 & 16 & NR \\
\hline & Hiroshima (2007) & $>60$ & 1.5 & 0.9 & NR \\
\hline & Hisayama (2008) & $>65$ & 33.2 & 14.9 & NR \\
\hline Dodge et al, ${ }^{20} 2012$ & Hisayama (1985) & $\geq 65$ & $6.7(5.0,8.3)$ & NR & 20.3 \\
\hline \multirow[t]{8}{*}{ (Review) } & Hisayama (1992) & $\geq 65$ & $5.6(4.4,7.1)$ & NR & 30.8 \\
\hline & Okinawa (1991-1992) & $\geq 65$ & $6.7(3.6,7.8)$ & NR & 47.1 \\
\hline & Hiroshima (1992-1996) & $\geq 65$ & $8.5(7.2,9.8)$ & $N R$ & 47.4 \\
\hline & Tajiri (1998) & $\geq 65$ & $8.5(7.2,9.9)$ & NR & $62.5^{\mathrm{c}}, 40.6^{\mathrm{d}}$ or $56.2^{\mathrm{d}}$ \\
\hline & Hisayama (1998) & $\geq 65$ & $7.1(5.7,8.5)$ & NR & 48.0 \\
\hline & Hisayama (2005) & $\geq 65$ & $12.5(|0.7| 4.2)$, & NR & 49.2 \\
\hline & Ama-cho (2008) & $\geq 65$ & $11.3(9.1,13.2)$ & NR & 63.5 \\
\hline & Hisayama $(2012)^{b}$ & $\geq 65$ & 17.9 & 12.3 & NR \\
\hline Ikejima et al, ${ }^{21} 2014$ & Apr 2006-Dec 2007 & & EOD & & \\
\hline \multirow[t]{3}{*}{ (regional study) } & Ibaraki, Gunma, Toyama, & $18-64$ & Standardized prevalence 47.6 & NR & VaD: 40.1 \\
\hline & Ehime, and Kumamoto & & per 100,000 persons & & AD: 24.3 \\
\hline & & & (95\% Cl: 47.I, 8.I) & & \\
\hline
\end{tabular}

Notes: aPrevalence data were recalculated and therefore may differ from those reported in the original papers; ${ }^{b}$ Kiyohara Y (20I5);22 cusing NINCDS-ADRDA ${ }^{75}$ and NINDAAIREN ${ }^{76}$ dementia diagnostic criteria; ${ }^{d}$ using DSM-IV ${ }^{77}$ diagnostic criteria for $A D$ and $\mathrm{VaD}$. Numbers differ due to diagnostic differences between assessors.

Abbreviations: AD, Alzheimer's disease; EOD, early-onset dementia; F, female; $\mathrm{M}$, male; NR, not reported; VaD, vascular dementia; yrs, years; popl, population; Cl, confidence interval; DSM-IV, Diagnostic and Statistical Manual of Mental Disorders IV; NINCDS-ADRDA, National Institute of Neurological and Communicative Disorders and Stroke and the Alzheimer's Disease and Related Disorders Association; NINDA-AIREN, National Institute for Neurological Disorders and Stroke-Association Internationale pour la Recherche et l'Enseignement en Neurosciences.

was also evident (about ninefold over 25 years), starting from $1.4 \%$ in 1985 , increasing to $1.8 \%$ in $1992,3.4 \%$ in $1998,6.1 \%$ in 2005 , and $12.3 \%$ in 2012. Conversely, the crude prevalence of $\mathrm{VaD}$ was largely unchanged over time, fluctuating at $2.4 \%$ in $1985,1.9 \%$ in $1992,1.7 \%$ in $1998,3.3 \%$ in 2005 , and $3.0 \%$ in 2012. Similar fluctuations were observed for the prevalence of dementia associated with other causes and unknown disease types (data not reported). The author suggested that only AD 
has consistently increased over time and that environmental factors may play a greater role than expected.

Consistent with the fifth cross-sectional Hisayama study, data from a 2012 national survey involving about 5000 people in six regions in Japan (Joetsu City, Niigata; Tone-machi, Ibaraki; Obu City, Aichi; Ama-cho, Shimane; Kitsuki City, Oita; and Imari City, Saga) indicated that the mean dementia prevalence rate in people aged $\geq 65$ years was $15.75 \%$ (95\% CI: $12.4,22.2) .{ }^{18}$ The survey also reported $\mathrm{AD}$ to be the most common form of dementia, accounting for $65.8 \%$ of cases, followed by $\mathrm{VaD}(17.9 \%)$, dementia with Lewy bodies (DLB)/Parkinson disease (4.1\%), and frontotemporal dementia $(0.9 \%)$. It was noted that the population aging rate was higher in all cities involved in the survey compared to the national average $(22.5 \%)$ with the exception of Obu City in Aichi, thereby limiting the generalizability of dementia prevalence at the national level.

Two reviews were identified that suggested that large variations in dementia and $\mathrm{AD}$ prevalence could be attributed to differences in diagnostic criteria, epidemiological methods, mortality rate, and demographics associated with the aging population, but that overall, the prevalence of dementia, particularly AD, was on the rise in Japan. ${ }^{19,20}$ The review by Catindig et $\mathrm{a}^{19}$ focused on the prevalence of dementia, AD and $\mathrm{VaD}$ in Asia and included six studies conducted in Japan. Dementia prevalence in Japan ranged from 4.2\% (Nakayama region) to $33.2 \%$ (Hisayama region), and $\mathrm{AD}$ prevalence ranged from $0.9 \%$ (Hiroshima region) to $16 \%$ (Osaki-Tajiri region). The review by Dodge et $\mathrm{a}^{20}$ examined changes in dementia prevalence and the relative prevalence of $\mathrm{AD}$ compared with VaD over time using eight large Japanese prevalence studies. After controlling for age and sex, the authors found that studies conducted in 1994, 1998, 2005, and 2008 had a higher prevalence of all-cause dementia when compared with the Okinawa 1991-1992 study. Likewise, the proportion of dementia cases attributed to $\mathrm{AD}$ was about $20 \%$ in 1985 increasing to around $60 \%$ over two decades.

One large population-based study was identified that focused on the prevalence of early onset dementia (EOD) in five catchment areas in Japan: Ibaraki, Gunma, Toyama, Ehime, and Kumamoto. ${ }^{21}$ EOD was defined as dementia with an onset age $<65$ years old. A study, conducted between April 1, 2006, and December 31, 2007, estimated the standardized prevalence of EOD to be 47.6 per 100,000 (95\% CI: 47.1, 48.1), a rate similar to that reported in Western countries (such as UK, USA, the Netherlands, and Finland). Unlike universityhospital-based studies that suggested that $\mathrm{AD}$ was the leading underlying cause of EOD in Japan, this community-based study showed that $\mathrm{VaD}$ was the most frequent cause of $\mathrm{EOD}$ (40.1\%), followed by $\operatorname{AD}(24.3 \%)$, head trauma ( $8.4 \%)$, and frontotemporal lobar degeneration (3.6\%).

\section{Incidence}

Three studies examining the incidence of dementia and/or AD in Japan were identified and are summarized in Table $2 .^{23-25}$ Matsui et $\mathrm{al}^{23}$ followed the 1985 prevalence cohort from the Hisayama study for 17 years, Yamada et $\mathrm{al}^{24}$ followed the 1992-1996 prevalence cohort from the Hiroshima study for 5.9 years, and Meguro et $\mathrm{al}^{25}$ followed a sub-sample of the 1998 Osaki-Tajiri study cohort for up to 7 years. Overall,

Table 2 Reported incidence of dementia and/or Alzheimer's disease in Japan

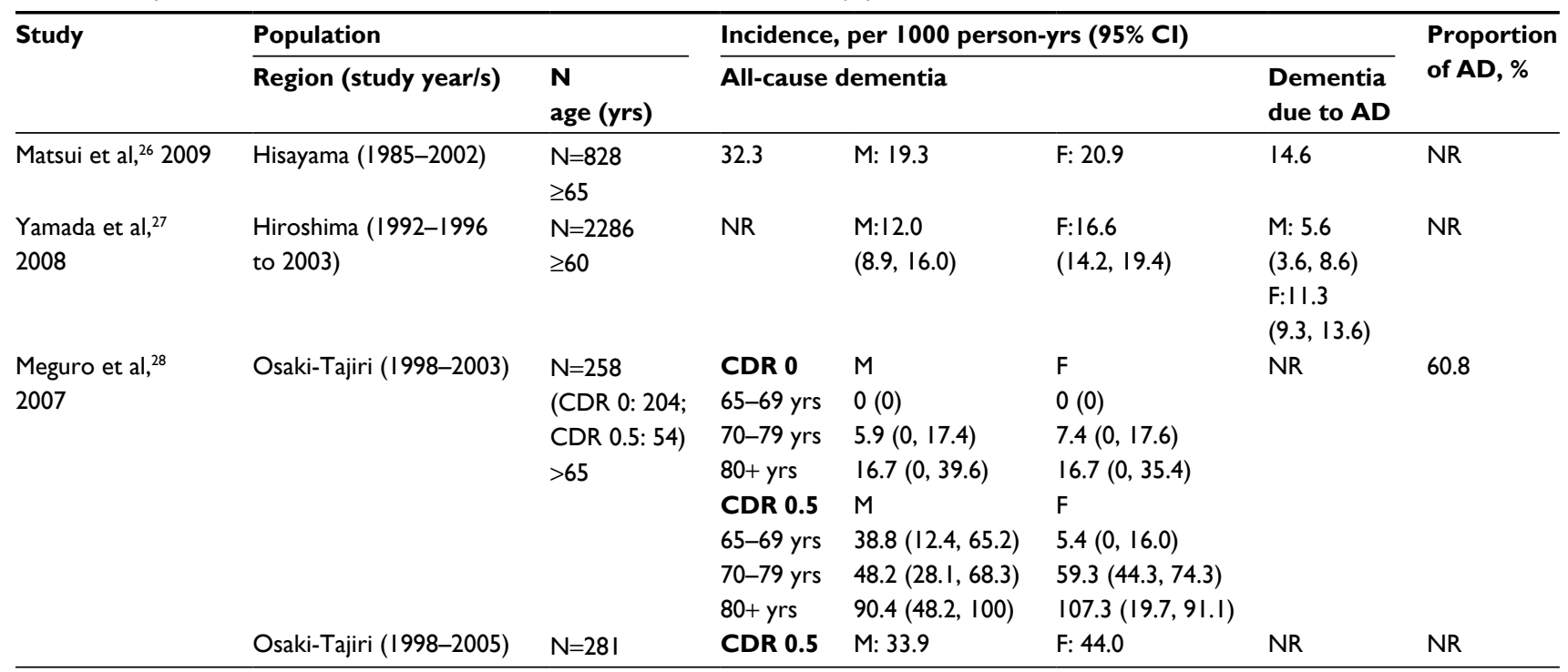

Notes: CDR 0 indicates healthy participant and CDR 0.5 indicates questionable dementia.

Abbreviations: $A D$, Alzheimer's disease; $C D R$, clinical dementia rating; $F$, female; $M$, male; $N R$, not reported; yrs, years; $C l$, confidence interval. 
these studies indicated a high risk for the development of dementia in the Japanese elderly population, with a greater incidence of $\mathrm{AD}$ compared with $\mathrm{VaD}$ being noted among those with a lower level of education.

The Hisayama study ${ }^{23}$ prospectively followed a cohort of 828 subjects aged $\geq 65$ years without dementia to determine the incidence of dementia and its subtypes. During the 17-year follow-up period, 275 subjects developed dementia corresponding to an incidence rate of 32.3 per 1000 personyears. The most frequent underlying type was AD (14.6 per 1000 person-years; $n=124)$, followed by $\operatorname{VaD}(9.5 ; n=81)$, DLB (1.4; $\mathrm{n}=12)$, combined dementia $(3.8 ; \mathrm{n}=33)$, and other types of dementia $(3.1, n=16)$. The incidences of $A D$, combined dementia, and other types of dementia increased with increasing age, particularly after the age of 85 years. This trend was not observed for VaD or DLB.

The Hiroshima study ${ }^{24}$ studied a cohort of 2286 dementiafree subjects aged $\geq 60$ years. In 2003, 206 cases of dementia were newly diagnosed, with AD being the predominant underlying cause. The incidence of all-cause dementia per 1000 person-years was 12.0 for men and 16.6 for women. The incidence of AD per 1000 person-years was 5.6 for men and 11.3 for women. Poisson regression models showed that increasing age and lower education were statistically significant risk factors for development of dementia and probable AD, whereas an association with gender did not reach statistical significance. ${ }^{26}$

The Osaki-Tajiri study ${ }^{25}$ investigated the incidence and associated risk factors for dementia in a community-based population aged over 65 years in northern Japan (OsakiTajiri). After a prevalence study in 1998, the dementia-free population were assessed in 2003 (5-year follow-up) and 2005 (7-year follow-up). The final participants included 204 (65.2\%) healthy adults (Clinical Dementia Rating, CDR 0) and $335(73.1 \%)$ people with questionable dementia (CDR $0.5)$. During the 5-year period, $3.9 \%(8 / 204)$ of the CDR 0 and $37.0 \%(20 / 54)$ of the CDR 0.5 participants developed dementia and during the 7-year period 40.2\% (113/281) of the CDR 0.5 participants developed dementia. AD was the predominant type of dementia (42.9\%), followed by AD with cerebrovascular disease (CVD) (17.9\%), VaD (17.9\%), and DLB (7.1\%). No CDR 0 participants in the 65-69 years group developed dementia, whereas rising incidence rates were observed in older age groups.

\section{Conversion from $\mathrm{MCl}$ to dementia or $\mathrm{AD}$ dementia}

A 5-year longitudinal epidemiological study was identified that estimated the rate at which subjects with MCI progress to dementia in Nakayama, Japan. ${ }^{27}$ Community dwellers aged 65 years were invited to participate over a 14-month period (January 1997-March 1998). The baseline sample comprised 104 subjects with MCI: 59 women and 45 men. During the 5-year follow-up period, eleven (10.6\%) subjects were diagnosed with $\mathrm{AD}$, five $(4.8 \%)$ with $\mathrm{VaD}$, and six $(5.8 \%)$ with dementia of other etiologies. There were nine (8.7\%) subjects who remained with a diagnosis of MCI and a further 40 (38.5\%) subjects who returned to normal. Overall, the annual conversion rate from MCI to dementia was reported to be $16.1 \%$ per 100 person-years and the conversion rate from MCI to AD dementia was $8.5 \%$ per 100 person-years. This conversion rate was reported to be consistent with those described previously (7\%-20\% per year), with variations likely related to different measures used to define MCI across the studies.

\section{Mortality and comorbidities in dementia}

Several studies were found linking dementia with higher morbidity and mortality. The Hisayama study ${ }^{23}$ involving 828 people over a 17 -year period reported the risk of death in dementia patients to be 1.7-fold higher than those without dementia. Here, median survival was 3.5 years in subjects with dementia compared with 5.8 years in those without dementia. The 10 -year survival rate was $13.6 \%$ in dementia patients, which was significantly lower than $29.3 \%$ observed in the age- and sex-matched controls (hazard ratio: 1.67; $95 \%$ CI: $1.31,2.13 ; p<0.0001)$. In a 7 -year survival study ${ }^{28}$ involving 272 patients, age, male gender, and hospitalization were reported to be significantly and independently related to an increased risk of mortality among dementia patients, while institutionalization was related to a decreased risk of mortality.

Data from MHLW show that cancer, heart disease, and stroke are the main causes of death in the general Japanese population, but respiratory failure or pneumonia is common in patients with $\mathrm{AD}$ and vascular diseases such as stroke and heart disease are commonly accompanied by VaD. ${ }^{15} \mathrm{~A}$ retrospective cohort study ${ }^{13}$ involving 121 patients reported severity of dementia, male gender, presence of CVD, and use of neuroleptics to be significantly and independently associated with aspiration pneumonia in $\mathrm{AD}$.

Also, a positive effect of treatment on life-time expectancy after onset of AD has been reported with the life-time expectancy in dementia patients receiving treatment with donepezil estimated to be 7.9 years compared with 5.3 years in the non-donepezil group. ${ }^{29}$

\section{Risk factors}

A large body of literature on potential risk factors associated with dementia/AD in Japan was identified, many with the aim 
to identify effective interventions that may prevent the onset of AD. Much of the evidence comes from two large high-quality epidemiological studies, ${ }^{22,24,26,30-40}$ with several prospective, retrospective, and case-control studies of lower quality also identified. ${ }^{25,41-50}$ A summary of risk factors reported for dementia and/or AD dementia is presented in Table 3.

Advanced age and lower education were consistently recognized as risk factors for AD. ${ }^{24-26,42}$ A significant

Table 3 Reported risk factors associated with Alzheimer's disease in Japan

\begin{tabular}{ll}
\hline Study & Study design \\
\hline Hisayama & Prospective cohort \\
study22,30-39 & (15-17 yrs \\
& follow-up)
\end{tabular}

Population

Risk factors

APOE- $\varepsilon$ 4/cholesterol/hypertension

- $A D$ was significantly higher in APOE- $\varepsilon 4$ carriers than in non-carriers

- Risk of senile plaque formation was significantly increased when the total cholesterol and LDL cholesterol exceeded a certain level $(224 \mathrm{mg} / \mathrm{dL}$ for the total cholesterol, $155 \mathrm{mg} / \mathrm{dL}$ for LDL cholesterol), and this association was independent of APOE- $\varepsilon 4$ allele

- Hypertension does not increase the onset risk of $A D$, but may affect $\mathrm{VaD}$

Diabetes/insulin resistance/glucose tolerance

- $D M$ is a significant risk factor for AD. Incidence per 1000 person-years = 14.2 vs 8.6 ; $p<0.05$. After adjusting for other risk factors, the RR for diabetic $A D$ was 2.18 -fold higher than non-diabetic $A D$

- Insulin resistance is associated with the accumulation of senile plaques

- There is a strong relationship between impaired glucose tolerance and $A D$ after adjusting for age/sex. Incidence per 1000 person-years = II.7 vs 8.6; $p=$ NS

- 2-hour post-load glucose levels were closely associated with an increased risk of $A D$ and $\mathrm{VaD}$, but no such association for fasting plasma glucose levels was observed

Lifestyle

- Long-term smoking is a significant risk factor for dementia, including $A D$, but discontinuation of smoking can reduce the risk even in the case of quitting in older age

- Physical activity contributes to the prevention of AD. More research required to work out the most effective kind and amount of exercise

- Small or moderate amount of alcohol can have protective effect on AD but studies warranted to justify the amount of alcohol intake in Japan to reduce $A D$ risk

Diet

- High levels of intake of fruits/fruit juice, potatoes, and fish, and low level of alcohol intake has a significant lower risk of the onset of $A D$ and $\mathrm{VaD}$

- Greater milk and dairy intake reduced the risk of dementia, especially $A D$

- No definite association between the amount of rice intake and the onset of dementia

Hiroshima

study $24,26,40$

Honma et al, ${ }^{41}$

2013

Sakurai et al, ${ }^{42}$

2011

Meguro et al, ${ }^{25}$

2007

Prospective cohort (5.9 yrs follow-up)

Prospective cohort ( 10 yrs follow-up)

Prospective cohort (mean follow-up of $39 \mathrm{mths}$; range 24-60 mths) Prospective cohort (5- and 7-yrs follow-up)

Fujiwara et al, ${ }^{43}$ Prospective cohort 2003

Urakami et al, ${ }^{44}$ Prospective cohort 2001
$A D$ dementia ( $\geq 60$ yrs)

$A D$ dementia (>65 yrs)

Probable AD (mean age 78.6 yrs)

CDR 0 (healthy older adults) and CDR 0.5 (questionable dementia)

General population

Dementia/AD
- $A D$ prevalence increased significantly with age and lower education

- Probable AD showed the most remarkable increase with age and decreased with increasing education level $(p=0.00 \mathrm{I})$

- IL-I $\beta$ and IL-6 values at the agitation stage were significantly associated with AD

- Subjects with DM or hypertension at baseline had significantly higher incidences of both $A D$ and $\mathrm{VaD}$

- Age, education level, and hypertension associated with progression to $A D$

- Age, MMSE, cognitive functions such as recent memory, and generalized atrophy were significant predictors of progression to $A D$

- Plasma A $\beta$ I-42 levels significantly correlated with age

- Conventional atherosclerotic risk factors (DBP and HbAlc) are associated with plasma $A \beta I-42$ concentrations and may be important in the detection and prevention of $A D$

- APOE polymorphism and estrogen receptor $\alpha$ gene closely related to $A D$

- Parents' birthing age closely related to $A D$ 
Table 3 (Continued)

\begin{tabular}{|c|c|c|c|}
\hline Study & Study design & Population & Risk factors \\
\hline $\begin{array}{l}\text { Shibata et al, }{ }^{45} \\
2009\end{array}$ & Case-control study & AD dementia & $\begin{array}{l}\text { - Association between a haplotype (G-A-A-G) of the TDP-43 gene and risk for AD } \\
\text { identified but none of the SNPs of the TDP-43 gene showed statistically significant } \\
\text { association with AD } \\
\text { - No synergetic association between the SNPs and APOE in AD }\end{array}$ \\
\hline $\begin{array}{l}\text { Tsutsumi } \\
\text { et al, }{ }^{46} 2007\end{array}$ & Case-control study & AD dementia & - The $-863 \mathrm{C}$ allele of TNF-alpha gene is a genetic risk factor for AD \\
\hline $\begin{array}{l}\text { Watanabe } \\
\text { et al, }{ }^{47} 2005\end{array}$ & Case-control study & $\begin{array}{l}\text { Dementia/AD } \\
(60-96 \text { yrs) }\end{array}$ & $\begin{array}{l}\text { - Decreased serum IGF-I level and the progression of carotid atherosclerosis could } \\
\text { play a role as independent risk factors of AD }\end{array}$ \\
\hline $\begin{array}{l}\text { Tanahashi } \\
\text { et al, }{ }^{48} 2004\end{array}$ & Case-control study & $\begin{array}{l}\text { AD dementia } \\
\text { (mean age of } \\
\text { onset } 70.0 \text { yrs) }\end{array}$ & $\begin{array}{l}\text { - Novel polymorphism (IVSII+90G } \rightarrow \text { A) of tau gene is associated with an increased risk } \\
\text { of early onset AD in males } \\
\text { - The polymorphic gene, saitohin, nested within the tau gene is not directly involved } \\
\text { in AD }\end{array}$ \\
\hline Grant, ${ }^{49} 2014$ & Review & AD dementia & $\begin{array}{l}\text { - Rising prevalence is related to the nutrition transition from a traditional to a Western } \\
\text { diet - alcohol consumption, animal product, meat and rice supply, and lung cancer } \\
\text { rates (smoking index) correlated highly with AD prevalence }\end{array}$ \\
\hline Asada, ${ }^{50} 2007$ & Review & AD dementia & $\begin{array}{l}\text { - High fish and/or omega-3 fatty acid consumption is inversely associated with the } \\
\text { development of dementia/AD } \\
\text { - Higher adherence to the Mediterranean diet is associated with lower risk of AD } \\
\text { - Abnormalities in glucose metabolism may have some effects on cognitive performance } \\
\text { - Association between antioxidants and AD onset is uncertain }\end{array}$ \\
\hline
\end{tabular}

Abbreviations: A $\beta$ I-42, $\beta$-amyloid peptide I-42; AD, Alzheimer's disease; APOE, apolipoprotein E; CDR, clinical dementia rating; DBP, diastolic blood pressure; DM, diabetes mellitus; DNA, deoxyribonucleic acid; HbAIc, hemoglobin A Ic; IGF-I, insulin-like growth factor-I; IL, interleukin; LDL, low-density lipoprotein; MMSE, mini-mental state examination; NS, nonsignificant, relative risk; SNPs, single nucleotide polymorphisms; TDP-43, TAR-DNA binding protein; TNF, tumor necrosis factor; VaD, vascular dementia; yrs, years; mths, months.

association between APOE- $\varepsilon 4$ and the onset of $\mathrm{AD}$ was also reported. ${ }^{30,31,43,44}$ The APOE is a protein related to fat metabolism and its risk can be modified according to the amount of fat intake. ${ }^{51}$ The literature suggested other key factors associated with increased risk for $\mathrm{AD}$ including diabetes mellitus and abnormal glucose tolerance; cardiovascular markers such as high levels of total cholesterol, low-density lipoprotein cholesterol, diastolic blood pressure, and hypertension; biomarkers such as increased plasma interleukin (IL)-1 $\beta$ and IL- 6 values at the agitation stage; and dietary and lifestyle factors such as low dairy and omega-3 fatty acid consumption, high alcohol consumption, long-term smoking, and physical inactivity.

One review ${ }^{49}$ suggested that the rising prevalence of $A D$ in Japan was related to the transition from a traditional diet, which is predominantly high in vegetable and grains, to a Western diet, which is more focused on meat and dairy.

\section{Diagnosis and treatment of AD in Japan}

In 2010, clinical practice guidelines for the management of dementing diseases were developed by six major societies in Japan including the Japanese Society of Psychiatry and Neurology, the Japan Society for Dementia Research, the Japanese Psychogeriatric Society, the Japan Geriatrics Society, the Japanese Society of Neurological Therapeutics, and the Japanese Society of Neurology, which outlined clinical signs, image findings, biochemical markers, and pharmacologic treatment guidance for AD. ${ }^{11,52}$ The 2010 guidelines also introduced non-pharmacologic therapies to relieve cognitive symptoms and provided recommendations for patient care. The 2010 guidelines and practical strategies identified in the literature are largely in line with the US Alzheimer's Disease Management Council (ADMC) consensus for the management of AD. ${ }^{53}$

\section{Diagnosis}

The 2010 guidelines recommended diagnosis of AD be based on psychiatric and neurological signs, imaging findings, and the presence of biomarkers, as summarized in Table 4 . A pattern of cognitive impairment characterized by recent memory impairment and delayed recall of memory tasks was noted as a particularly useful method of discrimination from a healthy person or from other dementing diseases. In the case of early onset of $\mathrm{AD}$, impairments other than the memory, such as aphasia, visuospatial cognition impairment, and visual constructional impairment, also often occur as the precursory symptoms. As AD progresses, disorientation and parietal lobe symptoms such as visuospatial impairment and constructional apraxia may be observed with a decline of insight into disease, psychiatric symptoms such as depression 
Table 4 Diagnosis of $A D$ in Japan as recommended by 2010 guidelines

\begin{tabular}{lll}
\hline Psychiatric/neurological signs & Imaging findings & Biomarkers \\
\hline - Recent memory impairment, delayed recall & - No abnormal cerebral structures present in & - A decrease in A 4 42 in cerebrospinal fluid and \\
of memory tasks and aphasia & CT or MRI with atrophy of mesial temporal & an increase in t-tau or P-tau values (Grade B) \\
- Visuospatial cognition impairment and visual & lobe (Grade A) & - Hematological tests to discriminate dementia \\
constructional impairment & - SPECT/FDG-PET shows a decrease in blood & from other diseases accompanied by dementia- \\
- Disorientation with parietal lobe symptoms & flow or glycometabolism disorder found & like symptoms including blood biochemistry \\
- Depression and apathy & in temporal lobes/parietal lobe and the & test, blood sugar, ammonia, thyroid hormone, \\
- "Lie-to-cover-up", "pretend-to-understand", & posterior cingulate gyrus (Grade B) & vitamin BI/BI2, and serologic reaction for \\
and theft paranoia & - Accumulation of amyloid found in amyloid & syphilis (Grade CI) \\
& imaging of PIB-PET (Grade C) & \\
\hline
\end{tabular}

Abbreviations: AD, Alzheimer's disease; CT, computerized tomography; MRI, magnetic resonance imaging; PIB, Pittsburgh compound-B; PET, positron emission tomography; SPECT/FDG, single photon emission CT/fluorodeoxyglucose

and apathy, and characteristic social behaviors such as "lieto-cover-up" and "pretend-to-understand" reactions. ${ }^{11,52}$ In some cases, theft paranoia can be seen from a relatively early stage but significant focal neurological symptoms are rarely observed in the early stages of the disease.

In Japan, single photon emission computed tomography (SPECT) is widely used for the diagnosis and clarification of dementia. SPECT can provide high specificity for AD against other types of dementia and can recognize diagnostic patterns in $\mathrm{AD} .{ }^{11,52}$

\section{Pharmacotherapy}

At the release of the 2010 guidelines, ${ }^{11}$ the cholinesterase inhibitor (ChEI) donepezil was the sole medication approved in Japan and indicated for AD dementia. Recommendation for other ChEIs (eg, galantamine and rivastigmine) and the $N$-methyl-D-aspartate (NMDA) receptor antagonist (memantine) were made based on meta-analyses of safety and efficacy of each drug. In 2012, subsequent to the approval of galantamine, rivastigmine, and memantine by the Pharmaceuticals and Medical Devices Agency, a compact version of the 2010 guidelines enclosed a treatment algorithm to inform the selection of therapeutic drugs based on disease progression, ${ }^{54}$ as summarized in Figure 2.

Given that the 2010 guidelines were released before the availability of these new medications, further guidance in drug selection, dose regimen, and drug switching in clinical practice has been provided, with several reviews and personal opinions on the practical treatment strategy for the management of $\mathrm{AD}$ identified in the systematic literature review. ${ }^{55-59}$

Most reviews focused on disease severity and patient characteristics as being the primary influence for drug selection. ${ }^{55-58}$ One author ${ }^{55}$ suggested that pharmacological properties of the drugs should also be taken into account, such as mechanism of action, half-life, and safety profile.
From a caregiver's point of view, another author ${ }^{57}$ suggested that galantamine was more effective than other drugs when administered in medium- and long term, resulting in a delay in admission to nursing home. A third author ${ }^{58}$ outlined a dose adjustment schedule based on the 2010 guidelines that suggested that drug doses should be started at a lower than recommended dose and then increased gradually to avoid adverse drug reactions.

Based on disease severity, ChEIs were recommended as the first-choice medicine. Donepezil was often mentioned as the first choice of medicine for mild AD dementia, as it is considered safe and efficacious even in patients aged $>85$ years; ${ }^{56,60}$ however, rivastigmine was also mentioned for use in patients with early symptoms of AD. ${ }^{56}$ Both ChEIs and memantine were recommended for moderate $\mathrm{AD}$ dementia, with the combination of ChEIs and memantine also as an option for both moderate and severe AD dementia, particularly among those who have trouble with daily living. ${ }^{56,59}$ Among AD patients with CVD or with BPSD, both galantamine and memantine were recommended. ${ }^{54,56}$

\section{Non-pharmacotherapy}

A number of non-pharmacotherapies for $\mathrm{AD}$ were mentioned in the guidelines as a means of managing or improving patient symptoms. ${ }^{11}$ For all therapies, it was noted that the strength of the evidence was weak due to lack of blinding and difficulty in efficacy measurement (Grade C1). A summary of non-pharmacotherapies used in the management of $\mathrm{AD}$ in Japan is provided in Table 5.

\section{Patient and caregiver care}

The 2010 guidelines noted that no patient care programs specific for AD are established in Japan. General dementia care is applied, which includes caregiver education and stress management (Grade B) and patient-oriented care and validation therapy (Grade C1). 

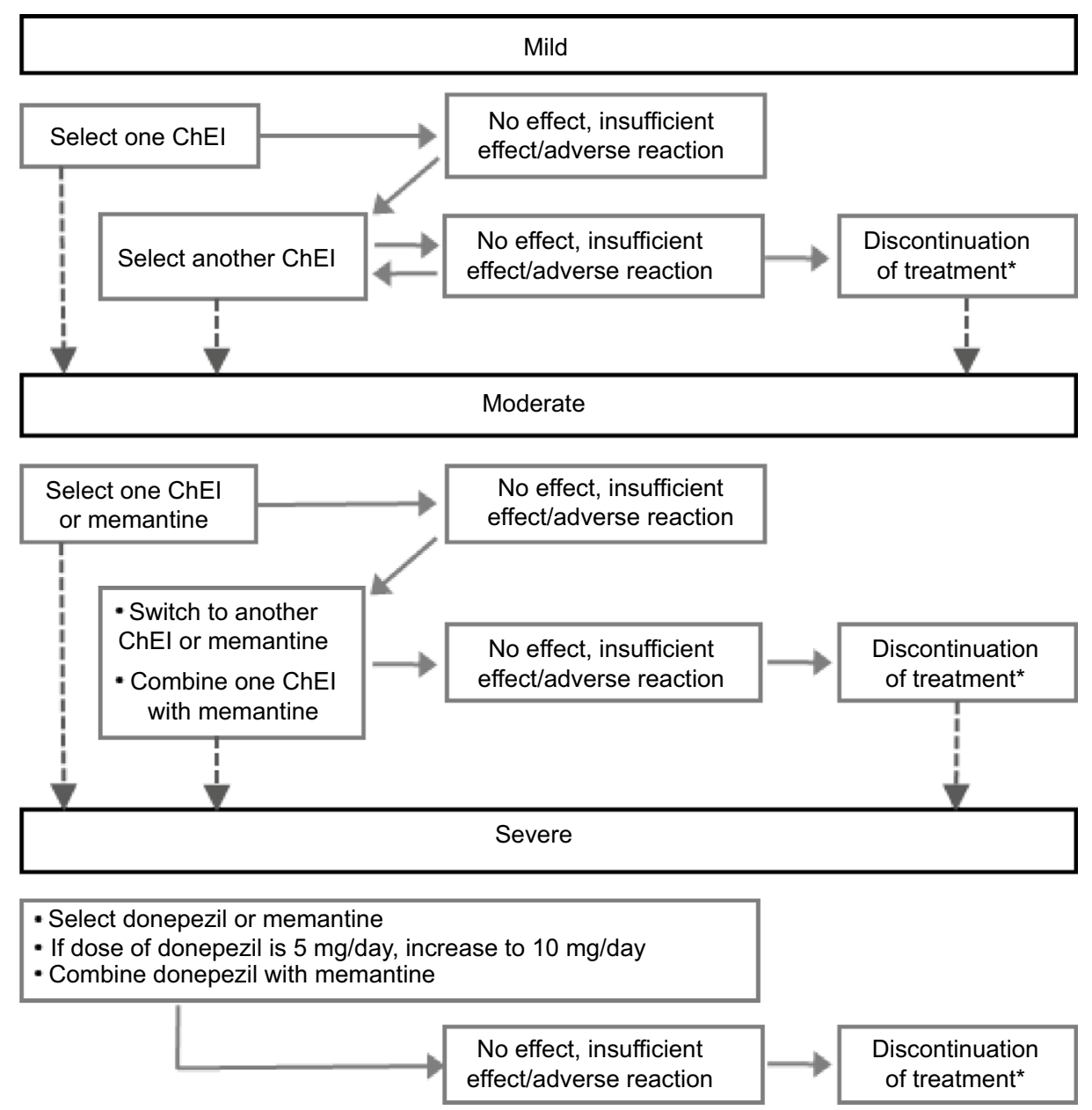

Figure 2 Treatment algorithm for the management of AD in Japan.

Notes: A dashed line indicates subsequent progression of the disease; *discontinuation of medication due to "no effect" should be carefully considered. ChEls included donepezil, galantamine, and rivastigmine. Translated and adapted from Japanese Society of Neurology. ${ }^{54}$

Abbreviations: AD, Alzheimer's disease; ChEls, cholinesterase inhibitors (donepezil, galantamine, and rivastigmine).

Table 5 Non-pharmacotherapies for AD assessed in the 2010 guidelines ${ }^{\mathrm{a}}$

\begin{tabular}{|c|c|}
\hline Treatment & Comments \\
\hline Reality orientation & $\begin{array}{l}\text { Intended to improve the behavioral and feeling disturbances that occur based on the wrong recognition of } \\
\text { surroundings by strengthening the reality orientation of patients }\end{array}$ \\
\hline Reminiscence therapy & $\begin{array}{l}\text { Intended to seek the psychological stability and personal unification of the elderly person by looking back on } \\
\text { the past experience and corresponding empathetically and receptively to the process }\end{array}$ \\
\hline Cognitive stimulation therapy & Intended to give brain stimulation and expect improvement of the cognitive function itself \\
\hline Kinesitherapy & $\begin{array}{l}\text { Inconsistent effectiveness recorded given the diversities in exercise types and intensity and different evaluation } \\
\text { methods }\end{array}$ \\
\hline Music therapy & $\begin{array}{l}\text { Defined as applying music as psychotherapy for mental and physical health using the functional effect that } \\
\text { music gives to human physiology and psychology }\end{array}$ \\
\hline Combination therapy & $\begin{array}{l}\text { Provide one intervention to the patient and a second intervention to the caregiver. Or combination of more } \\
\text { than two non-pharmacotherapies to the patient, such as walking and conversation or reality orientation } \\
\text { training, cognitive training, activities of daily living training, and psychomotor training }\end{array}$ \\
\hline Phototherapy & $\begin{array}{l}\text { Performed for the purpose of decreasing sleep-wake rhythm and abnormal behavior during the night in } \\
\text { dementia patients }\end{array}$ \\
\hline Cerebrospinal fluid shunt operation & Performed to clear amyloid protein in cerebrospinal fluid, but appears to be ineffective (Grade D) \\
\hline
\end{tabular}

Note: ${ }^{a}$ In all therapies, the strength of the clinical evidence was regarded as weak due to lack of blinding and difficulty in efficacy measurement (Grade $\mathrm{Cl}$ ).

Abbreviation: AD, Alzheimer's disease. 
To reduce burden on the family and to relieve stress and depression caused by long-term care of AD patients, the guidelines highlighted the importance of providing caregivers access to stress management, support groups, and care resources that may include counseling, kinesitherapy, workshops, helpers, day service, and short stays for the family. Also, although there is no evidence indicating the efficacy, validity, or reliability of patient-oriented care, the guidelines recommend that patient-oriented care should be introduced from a humanitarian and ethical point of view, as it is essential to the establishment of self-respect in the advanced stage of AD patients. Patient-oriented care puts quality of person in the center of care in contrast to conventional care where medical correspondence is at the core. Validation therapy is an approach of dementia care similar to patient-oriented care, focusing on acceptance and sympathy.

General principles regarding the attitude of caregivers to patient care were introduced in the 2010 guidelines ${ }^{11}$ and were based on those recommended by the American Psychiatric Association. The recommendations were as follows: understand that the condition will involve a decline in the patient's ability and not to have high expectations; be careful about the rapid progress and appearance of a new symptom; try simple instructions and demands, and when the patient is confused or angry, change the demand; avoid difficult work that may lead to a failure; do not force the patient to face their impairment; try to behave in a calm, stable, and supportive manner; avoid an unnecessary change; and explain things in as detailed a way as possible, giving hints to keep the patient orientated.

\section{Alzheimer drugs in clinical practice}

Based on published reviews and personal opinions, treatment initiation for dementia, MCI, or AD dementia is recommended to be initiated as early as possible, ${ }^{56,59}$ with treatment efficacy to be evaluated every 2-3 months. Switching medications is to be considered only when no response is observed following $\sim 6$ months of treatment and switching to a new drug that is indicated for the same disease severity ${ }^{56}$ and to be administered immediately. ${ }^{58}$ If the previous $\mathrm{ChEI}$ is discontinued due to adverse events (AEs), it is recommended that the new $\mathrm{ChEI}$ is administered after confirmation that the patients is free from the AEs. ${ }^{58}$ Pharmacotherapy should be continued until either intolerance to AEs or when the disease progresses to the terminal stage (ie, unable to take food due to dysphagia or requiring nursing care). ${ }^{56,58}$

It should be noted that the majority of pharmacotherapies recommended for the treatment of $\mathrm{AD}$ dementia (donepezil, galantamine, rivastigmine, and memantine) act by treating
AD symptoms. Disease-modifying therapies that target the underlying etiologies of the disease are still under development. Patients treated with the four currently licensed drugs will eventually experience deterioration of their symptoms due to the natural progression of the disease process. Therefore, drug treatments for cognitive symptoms, controlling of BPSD, non-pharmacological intervention, and care programs to improve the quality of life for both patients and caregivers are of equal importance.

There were no studies identified in the systematic literature review that reported on treatment or prescribing patterns in the management of cognitive function among patients with AD dementia in Japan. However, one claims database analysis was located that examined trends in the use of psychotropic medications for tackling severe agitation, aggression, and psychosis associated with BPSD in Japanese patients. ${ }^{61}$ The study utilized data from a 2002-2010 survey of Medical Care Activities in Public Health Insurance, a nationally representative cross-sectional survey of claims data for the month of June in every year. Data from 15,591 patients with dementia aged $\geq 65$ years who were prescribed ChEIs at ambulatory care visits revealed, in 2008-2010, that the most frequently prescribed psychotropic medications were sedative-hypnotics (37.5\%), antipsychotics (24.9\%), antidepressants (13.0\%), and mood-stabilizers (2.9\%). Between 2002-2004 and 20082010 , use of second-generation antipsychotics increased from $5.0 \%$ to $12.0 \%$, while use of first-generation antipsychotics decreased from $20.6 \%$ to $12.9 \%$. The results suggested a slight increase in the off-label use of antipsychotics over time.

\section{Discussion}

This systematic literature review provides a comprehensive overview of the epidemiology and recommended clinical practice for the diagnosis and management of AD in Japan and reveals a paucity of evidence relating to real-world treatment patterns for this disease in Japan. With life expectancy in Japan among the highest in the world, AD will increasingly become a significant health care problem. This is because disability associated with dementia, and the resources needed to care for patients with $\mathrm{AD}$, increases with age. Indeed, the social burden associated with dementia in Japan is reported to have increased 2.2 times from $¥ 755.9$ billion in 2002 to $¥ 1,653.4$ billion in $2011 .{ }^{62}$

Several studies were identified that demonstrate the prevalence of dementia to be increasing in Japan, driven by population aging, growing awareness of $\mathrm{AD}$, and a variety of other potential risk factors. ${ }^{14,17-21,23,24,27,57}$ These findings are in contrast to that reported in the USA, where the prevalence 
and incidence of dementia have been stable or declining, and the risk of $\mathrm{AD}$ is presumed to remain constant. ${ }^{63,64} \mathrm{~A}$ key contributor to the rise in overall dementia in Japan is the steady increase in $\mathrm{AD}$ prevalence, with $\mathrm{AD}$ taking over from $\mathrm{VaD}$ as the most commonly cited cause of dementia. In the Hisayama study, AD prevalence among those aged $\geq 65$ years increased from $1.4 \%$ in 1985 to around $12.3 \%$ in 2012 ; correlating with an increase in overall dementia from $6.7 \%$ in 1985 to $17.9 \%$ in $2012 .^{20,22}$

Trends in incidence of dementia in Japan illustrate older age and female gender to be associated with AD more than $\mathrm{VaD}$, with reasons for growth in $\mathrm{AD}$ beyond the speed of aging or protective factors for dementia continuing to be explored. ${ }^{23-26}$ Several studies showed education level, presence of diabetes, transition to a more Western diet, and lifestyle factors such as high alcohol intake and low physical activity to be associated with an increased risk of AD in Japan. ${ }^{22,25,32-34,49,50}$ Many of these risk factors correlate with those identified elsewhere, where changes in education and socioeconomic status, a decline in CVD, and an increasing prevalence of hypertension and diabetes have been offered as possible explanations for influencing the development of dementia in North America, the UK, and Europe. ${ }^{64-71}$

The identification of numerous risk factors for $\mathrm{AD}$ in Japan provides multiple pathways to potentially target to prevent or reduce the risk of developing AD dementia in later age. Public health interventions directed at improving diet and the level of physical activity and continued focus on identifying and managing cardiovascular and CVD are some examples that may provide benefit by slowing the development of AD. Continuous research to strengthen the evidence to ascertain causality and to identify genetic risk factors for $\mathrm{AD}$ is also needed.

Early detection and early treatment are considered highly important in the management of AD and dementia. ${ }^{11,52}$ The current diagnosis of $\mathrm{AD}$ relies on the presence of cognitive impairment and ruling out of other diseases. Patients who do not meet the clinical criteria for dementia or AD dementia may be classified as having MCI; however, the diagnosis of MCI does not necessarily predict the development of dementia or AD dementia. ${ }^{27}$ The development of more reliable tests to improve confidence in $\mathrm{AD}$ diagnosis, including improvements in biomarker tests to detect $A \beta$, would allow for initiation of early intervention and improved patient outcomes and quality of life. ${ }^{72}$

The current focus of research for many AD treatments is to delay the development of the disease. Indeed, if interventions could either delay the onset of dementia or disease progression by one or two years, it is projected that the global burden of this disease would be significantly reduced, with more than $20 \%$ fewer cases of AD occurring in $2050 . .^{73}$ The ChEIs (donepezil, galantamine, rivastigmine) and NMDA receptor antagonists (memantine) are currently approved in Japan and indicated for AD dementia. Of note, these pharmacotherapies treat the symptoms of $\mathrm{AD}$ but have not been shown to prevent the progression of AD itself. Therefore, non-pharmacological interventions and patient care programs focused on controlling behavioral and psychological symptoms of dementia play an important role in improving quality of life for patients and their caregivers. Disease-modifying therapies that target the underlying etiologies of the disease are still in development.

Clinical guidelines for the management of dementia were released in 2010 providing general treatment guidance for AD. A revised version of the guidelines was published in August 2017, which updated the chapters on diagnosis, pharmacotherapy, non-pharmacotherapy, and patient and caregiver care. ${ }^{74}$ Diagnosis of AD cited upgraded diagnostic criteria and the usage of amyloid PET. There was no significant change in the treatment algorithm for $\mathrm{AD}$, but recent evidence from RCTs, systematic literature reviews, and meta-analysis were added on the anti-AD medications. This systematic review identified a paucity of data on the real-world clinical practice pattern of AD in Japan. Claims database analyses are warranted to provide a treatment pattern and the market uptake of those anti-AD medications.

Our study has limitations, with the focus being on the qualitative synthesis of English and Japanese literature. Due to the nature of the evidence, no meta-analyses or publication tests such as a funnel plot analysis were conducted. Also, there is an assumption that Japanese articles were correctly identified and translated into the English language. Our review is, therefore, potentially subject to publication bias and selective reporting within studies.

\section{Conclusion}

With the world's fastest aging population, the burden of AD in Japan is growing. Strategies to improve diagnosis, treatment, and manage risk factors have the potential to reduce the overall burden on families, caregivers, and the health care system. New interventions that slow disease progression or delay disease onset would have a major impact on reducing the burden of this disease on the health system.

\section{Acknowledgments}

The authors thank Wei Du from TransPerfect for assistance with translations of Japanese language articles. This review was funded by Eli Lilly and Company. 


\section{Disclosure}

William Montgomery, Tomomi Nakamura, and Kaname Ueda are all employees at Eli Lilly and Company. Margaret Jorgensen, Shari Stathis, and Yuanyuan Cheng are employed by Health Technology Analysts Pty Ltd, which was commissioned by Eli Lilly and Company to undertake this review of Alzheimer's disease in Japan. The authors report no other conflicts of interest in this work.

\section{References}

1. Alzheimer's Association. 2016 Alzheimer's disease facts and figures. Alzheimers Dement. 2016;12(4):459-509.

2. Alzheimers Disease International. Improving healthcare for people living with dementia: Coverage, quality and costs now and in the future. World Alzheimer Report 2016: The Global Voice on Dementia. 2016. Available from: https:/www.alz.co.uk/research/world-report-2016. Accessed May 11, 2017.

3. Kyodo Staff Report. Japan grapples with $¥ 14.5$ trillion dementia costs. The Japan Times. May 29, 2015; National, Science and Health. Available from: http://www.japantimes.co.jp/news/2015/05/29/national/sciencehealth/japan-grapples-with-\%C2\%A514-5-trillion-dementia-costs/\# WDy8o0Yyaao. Accessed June 25, 2016.

4. Kyodo Staff Report. Number of dementia patients to reach around 7 million in Japan in 2025. The Japan Times. Jan 8, 2015; National, Science and Health. http://www.japantimes.co.jp/news/2015/01/08/national/ number-dementia-patients-reach-around-7-million-japan-2025/\# WDzC4EYyaao. Accessed June 25, 2016.

5. Petersen RC. Mild cognitive impairment as a diagnostic entity. J Intern Med. 2004;256(3):183-194.

6. Gauthier S, Reisberg B, Zaudig M, et al. Mild cognitive impairment. Lancet. 2006;367(9518):1262-1270.

7. Albert MS, DeKosky ST, Dickson D, et al. The diagnosis of mild cognitive impairment due to Alzheimer's disease: recommendations from the National Institute on Aging-Alzheimer's Association workgroups on diagnostic guidelines for Alzheimer's disease. Alzheimers Dement. 2011;7(3):270-279.

8. American Psychiatric Association: Diagnostic and Statistical Manual of Mental Disorders. 5th ed. Arlington, VA: American Psychiatric Association; 2013.

9. Bozoki A, Giordani B, Heidebrink J, Berent S, Foster N. Mild cognitive impairments predict dementia in nondemented elderly patients with memory loss. Arch Neurol. 2001;58:411-416.

10. Hersch EC, Falzgraf S. Management of the behavioral and psychological symptoms of dementia. Clin Interv Aging. 2007;2(4):611-621.

11. Japanese Society of Neurology. [Chapter V: Alzheimer's disease. Dementia Disease Treatment Guidelines 2010]. Available from: https:// www.neurology-jp.org/guidelinem/nintisyo.html. Accessed December 24, 2015. Japanese.

12. FDA Alert. Information for healthcare professionals: conventional antipsychotics. 2008. Available from: http://www.fda.gov/Drugs/ DrugSafety/PostmarketDrugSafetyInformationforPatientsandProviders/ ucm124830.htm. Accessed May 10, 2016.

13. Wada H, Nakajoh K, Suzuki T, Ohrui T. Risk factors of aspiration pneumonia in Alzheimer's disease patients. Gerontology. 2001;47: 271-276.

14. Meguro K, Ishii H, Yamaguchi S, et al. Prevalence of dementia and dementing diseases in Japan: the Tajiri project. Arch Neurol. 2002;59(7):1109-1114.

15. Ministry of Health Labour and Welfare. Statistics of annual population census 2010. Available from: http://www.mhlw.go.jp/toukei/saikin/hw/ jinkou/suikei10/index.html. Accessed May 5, 2016.

16. Moher D, Liberati A, Tetzlaff J, Altman DG, Group P. Preferred reporting items for systematic reviews and meta-analyses: the PRISMA statement. J Clin Epidemiol. 2009;62(10):1006-1012.
17. Sekita A, Ninomiya T, Tanizaki Y, et al. Trends in prevalence of Alzheimer's disease and vascular dementia in a Japanese community: the Hisayama Study. Acta Psychiatr Scand. 2010;122(4):319-325.

18. Asada T. [Prevalence of dementia in Japan: past, present and future]. Rinsho Shinkeigaku. 2012;52(11):962-964. Japanese.

19. Catindig JA, Venketasubramanian N, Ikram MK, Chen C. Epidemiology of dementia in Asia: insights on prevalence, trends and novel risk factors. J Neurol Sci. 2012;321(1-2):11-16.

20. Dodge HH, Buracchio TJ, Fisher GG, et al. Trends in the prevalence of dementia in Japan. Int J Alzheimers Dis. 2012;2012:956354.

21. Ikejima $C$, Ikeda $M$, Hashimoto $M$, et al. Multicenter populationbased study on the prevalence of early onset dementia in Japan: vascular dementia as its prominent cause. Psychiatry Clin Neurosci. 2014;68(3):216-224.

22. Kiyohara Y. [Life science to support preemptive medicine: environmental determinants of Alzheimer's disease]. Exp Med. 2015;33(7):10321037. Japanese.

23. Matsui Y, Tanizaki Y, Arima $\mathrm{H}$, et al. Incidence and survival of dementia in a general population of Japanese elderly: the Hisayama study. J Neurol Neurosurg Psychiatry. 2009;80(4):366-370.

24. Yamada M, Mimori Y, Kasagi F, et al. Incidence of dementia, Alzheimer disease, and vascular dementia in a Japanese population: Radiation Effects Research Foundation Adult Health Study. Neuroepidemiology. 2008;30(3):152-160.

25. Meguro K, Ishii H, Kasuya M, et al. Incidence of dementia and associated risk factors in Japan: the Osaki-Tajiri Project. J Neurol Sci. 2007;260(1-2):175-182.

26. Yamada M, Mimori Y, Kasagi F, Miyachi T, Ohshita T, Sasaki H. Incidence and risks of dementia in Japanese women: Radiation Effects Research Foundation Adult Health Study. J Neurol Sci. 2009;283(1-2):57-61.

27. Ishikawa T, Ikeda M. Mild cognitive impairment in a population-based epidemiological study. Psychogeriatrics. 2007;7:104-108.

28. Nohtomi A, Tsukamoto S. Predictors of mortality in patients with dementia: a seven-year survival study. Psychogeriatrics. 2004;4(1):A37.

29. Meguro K, Kasai M, Akanuma K, Meguro M, Ishii H, Yamaguchi S. Donepezil and life expectancy in Alzheimer's disease: a retrospective analysis in the Tajiri Project. BMC Neurol. 2014;14:83.

30. Ohara T, Ninomiya T, Kubo M, et al. Apolipoprotein genotype for prediction of Alzheimer's disease in older Japanese: the Hisayama study. J Am Geriatr Soc. 2011;59(6):1074-1079.

31. Iwaki T. [Glucose tolerance disorder as a risk factor for Alzheimer's disease] J Clin Experiment Med. 2012;242(8):604-605. Japanese.

32. Ohara T. [Glucose tolerance status and risk of dementia in the community: the Hisayama study]. Seishin Shinkeigaku Zasshi: Psychiatria et Neurologia Japonica. 2013;115(1):90-97. Japanese.

33. Ozawa M, Ninomiya T, Ohara T, et al. Dietary patterns and risk of dementia in an elderly Japanese population: the Hisayama study. Am J Clinic Nutrit. 2013;97(5):1076-1082.

34. Ozawa M, Ohara T, Ninomiya T, et al. Milk and dairy consumption and risk of dementia in an elderly Japanese population: the Hisayama study. J Am Geriatr Soc. 2014;62(7):1224-1230.

35. Kiyohara Y. [Background factors and risk factors for dementia as seen from the Hisayama-machi study]. Biomed Therap. 2008;42(6):635-638. Japanese.

36. Kiyohara Y. [Diabetes mellitus and Alzheimer's disease]. Bio Clinica. 2009;24(3):280-284. Japanese.

37. Kiyohara Y. [Dementia up to date: epidemiology of dementia-based on Hisayama study]. Mol Cerebrovasc Med. 2010;9(2):147-153. Japanese.

38. Kiyohara Y. [Cognitive function and hypertension: epidemiology of dementia - Hisayama study]. Blood Pressure. 2012;19(8):684-688. Japanese.

39. Ninomiya T, Ohara T, Hirakawa Y, et al. Midlife and late-life blood pressure and dementia in japanese elderly: the Hisayama study. Hypertension. 2011;58(1):22-28.

40. Yamada M, Kasagi F, Sasaki H, Masunari N, Mimori Y, Suzuki G. Association between dementia and midlife risk factors: the Radiation Effects Research Foundation Adult Health Study. J Am Geriatr Soc. 2003;51(3):410-414. 
41. Honma T, Hatta K, Hitomi Y, et al. Increased systemic inflammatory interleukin-1s and interleukin-6 during agitation as predictors of Alzheimer's disease. Int J Geriatr Psychiatry. 2013;28(3):233-241.

42. Sakurai H, Hanyu H, Sato T, et al. Vascular risk factors and progression in Alzheimer's disease. Geriatr Gerontol Int. 2011;11(2):211-214.

43. Fujiwara Y, Takahashi M, Tanaka M, Hoshi T, Someya T, Shinkai S. Relationships between plasma beta-amyloid peptide 1-42 and atherosclerotic risk factors in community-based older populations. Gerontology. 2003;49(6):374-379.

44. Urakami K, Wakutani Y, Nakajima K. [Pathogenetic mechanism of Alzheimer's disease - epidemiology and risk factors of dementia]. Jpn J Neuropsychopharmacol. 2001;21(6):222. Japanese.

45. Shibata N, Ohnuma T, Baba H, Arai H. Genetic association analysis between TDP-43 polymorphisms and Alzheimer's disease in a Japanese population. Dement Geriatr Cogn Dis. 2009;28(4):325-329.

46. Tsutsumi A, Nishiguchi M, Kikuyama H, Houkyou A, Koh I, Yoneda $\mathrm{H}$. Tumor necrosis factor-alpha-863A/C polymorphism is associated with Alzheimer's disease. Psychiatry Clin Neurosci. 2007;61(2):S16.

47. Watanabe T, Miyazaki A, Katagiri T, Yamamoto H, Idei T, Iguchi T. Relationship between serum insulin-like growth factor-1 levels and Alzheimer's disease and vascular dementia. J Am Geriatr Soc. 2005;53(10):1748-1753.

48. Tanahashi H, Asada T, Tabira T. Association between Tau polymorphism and male early-onset Alzheimer's disease. NeuroReport. 2004;15(1):175-179.

49. Grant WB. Trends in diet and Alzheimer's disease during the nutrition transition in Japan and developing countries. J Alzheimers Dis. 2014;38(3):611-620.

50. Asada T. Prevention of Alzheimer's disease: putative nutritive factors. Psychogeriatrics. 2007;7(3):125-131.

51. Liu CC, Liu CC, Kanekiyo T, Xu H, Bu G. Apolipoprotein E and Alzheimer disease: risk, mechanisms and therapy. Nat Rev Neurol. 2013;9(2):106-118.

52. Tokuda T. [Disease review: diagnosis and treatment of Alzheimer's disease]. SRL Hokan Quarterly. 2013;33(4):19-29. Japanese.

53. Muramatsu K, Yoshizaki T. [Therapeutic drug selection for Alzheimer's disease treatment]. Shinryo [Diagnosis and Treatment]. 2015;103(7):889-894. Japanese.

54. Japanese Society of Neurology. Chapter V: Alzheimer's disease. In: Dementia disease treatment guidelines 2010: Compact Edition 2012. Available from: https:/www.neurology-jp.org/guidelinem/nintisyo_ compact.html. Accessed May 10, 2016.

55. Arai H. [Practical strategy of pharmacotherapy for Alzheimer's disease from the clinical point of view]. Cogn Dement. 2011;10(Suppl 1): 35-39. Japanese.

56. Endo H. [Selection criteria of drugs for Alzheimer's disease treatment]. J New Remed Clinics. 2013;62(1):101-103. Japanese.

57. Endo H, Miura H, Satake S. [New development of therapuetic strategy for Alzheimer's disease - the merit of drugs for care giver of Alzheimer's disease]. Cogn Dement. 2011;10(Suppl 1):55-58. Japanese.

58. Nakamura Y. [New era of drugs for Alzheimer-type dementia: practical strategy for four antidementia drugs and classification of disease severity of dementia]. Medicinal. 2012;2(5):82-88. Japanese.

59. Morita K, Shoji Y, Fujiki R, Hiroyuki Y, Masayuki I. [Therapeutic strategy for Alzheimer-type dementia]. Jpn J Clin and Experiment Med. 2014;91(12):1641-1646. Japanese.
60. Arai H. [Current therapies in dementia]. Nihon Ronen Igakkai Zasshi. 2004;41:310-313. Japanese.

61. Okumura Y, Togo T, Fujita J. Trends in use of psychotropic medications among patients treated with cholinesterase inhibitors in Japan from 2002 to 2010. Int Psychogeriatr. 2015;27(3):407-415.

62. Hanaoka O, Matsumoto K, Kitazawa T, Seto K, Fujita S, Hasegawa T. [Social burden associated with dementia in Japan]. JJpn Soc Healthcare Manage. 2015;2-K-32(16 (Suppl)):280. Japanese.

63. Brookmeyer R, Gray S, Kawas C. Projections of Alzheimer's disease in the United States and the public health impact of delaying disease onset. Am J Public Health. 1998;88(9):1337-1342.

64. Rocca WA, Petersen RC, Knopman DS, et al. Trends in the incidence and prevalence of Alzheimer's disease, dementia, and cognitive impairment in the United States. Alzheimers Dement. 2011;7(1):80-93.

65. Ott A, Stolk RP, van Harskamp F, Pols HA, Hofman A, Breteler MM. Diabetes mellitus and the risk of dementia: the Rotterdam study. Neurology. 1999;53(9):1937-1942.

66. Ott A, van Rossum CT, van Harskamp F, van de Mheen H, Hofman A, Breteler MM. Education and the incidence of dementia in a large population-based study: the Rotterdam Study. Neurology. 1999;52(3): 663-666.

67. Stern Y. Cognitive reserve and Alzheimer disease. Alzheimer Dis Assoc Disord. 2006;20(2):112-117.

68. Gamaldo A, Moghekar A, Kilada S, Resnick SM, Zonderman AB, O'Brien R. Effect of a clinical stroke on the risk of dementia in a prospective cohort. Neurology. 2006;67(8):1363-1369.

69. Ivan C, Seshadri S, Beiser A, et al. Dementia after stroke: the Framingham Study. Stroke. 2004;35(6):1264-1268.

70. Fratiglioni L, Paillard-Borg S, Winblad B. An active and socially integrated lifestyle in late life might protect against dementia. Lancet Neurol. 2004;3(6):343-353.

71. Xu WL, Qiu CX, Wahlin A, Winblad B, Fratiglioni L. Diabetes mellitus and risk of dementia in the Kungsholmen project: a 6-year follow-up study. Neurology. 2004;63(7):1181-1186

72. Hornberger J, Bae J, Watson I, Johnston J, Happich M. Clinical and cost implications of amyloid beta detection with amyloid beta positron emission tomography imaging in early Alzheimer's disease - the case of florbetapir. Curr Med Res Opin. 2017;33(4):675-685.

73. Brookmeyer R, Johnson E, Ziegler-Graham K, Arrighi HM. Forecasting the global burden of Alzheimer's disease. Alzheimers Dement. 2007;3(3): 186-191.

74. Japanese Society of Neurology. [Chapter 6: Alzheimer's disease. Dementia Disease Treatment Guidelines 2017: Igaku-shoin]. Japanese. Available from: https://www.neurology-jp.org/guidelinem/index.html. Accessed October 10, 2017.

75. McKhann G, Drachman D, Folstein M, Katzman R, Price D, Stadlan EM. Clinical diagnosis of Alzheimer's disease: report of the NINCDS-ADRDA Work Group under the auspices of Department of Health and Human Services Task Force on Alzheimer's Disease. Neurology. 1984;34(7):939-944.

76. Roman GC, Tatemichi TK, Erkinjuntti T, et al. Vascular dementia: diagnostic criteria for research studies. Report of the NINDS-AIREN International Workshop. Neurology. 1993;43(2):250-260.

77. American Psychiatric Association. Diagnostic and Statistical Manual of Mental Disorders. 4th ed, text rev. Washington, DC. American Psychiatric Association; 2000.
ClinicoEconomics and Outcomes Research

\section{Publish your work in this journal}

ClinicoEconomics and Outcomes Research is an international, peerreviewed open-access journal focusing on health technology assessment, pharmacoeconomics and outcomes research in the areas of diagnosis, medical devices, and clinical, surgical and pharmacological intervention. The economic impact of health policy and health systems organization also constitute important areas of coverage. The manuscript management system is completely online and includes a very quick and fair peer-review system, which is all easy to use. Visit http://www.dovepress.com/testimonials.php to read real quotes from published authors. 